\title{
Variation in hematological parameters in adult male and female smokers in Quetta city
}

\author{
Mohadisa Arbab ${ }^{1}$, Zahra Batool $^{1}$, Hira Afsheen ${ }^{1}$, Hamida Ali $^{1}$, \\ Muhammad Naeem ${ }^{2}$, Nabeela Tariq ${ }^{1}$, Tahir Hameed ${ }^{3 *}$, Mohammad \\ Masood Tariq ${ }^{3}$ and Farhat Abbas Bukhari ${ }^{3}$ \\ 1. Department of Zoology, Sardar Bahadur Khan Women University, Quetta-Pakistan \\ 2. Microbiology Department, University of Balochistan, Quetta-Pakistan \\ 3. Center of Advance Studies in Vaccinology and Biotechnology, University of Balochistan, Quetta-Pakistan \\ *Corresponding author's email: tahirquetta@hotmail.com \\ Citation \\ Mohadisa Arbab, Zahra Batool, Hira Afsheen, Hamida Ali, Muhammad Naeem, Nabeela Tariq, Tahir Hameed, \\ Mohammad Masood Tariq and Farhat Abbas Bukhari. Variation in hematological parameters in adult male and \\ female smokers in Quetta city. Pure and Applied Biology. Vol. 8, Issue 1, pp866-872. \\ http://dx.doi.org/10.19045/bspab.2019.80028

\begin{tabular}{|c|c|c|c|}
\hline Received: $13 / 11 / 2018$ & Revised: $26 / 02 / 2019$ & Accepted: 04/03/2019 & Online First: $15 / 03 / 2019$ \\
\hline
\end{tabular}

\section{Abstract}

Smoking is the second leading cause of death in the world. It has many adverse effects on organs and systems of body. Rapidly increased rate of smoking in all over the world is the largest threat for the health. Smoking may change different cellular components of blood. Different chemicals especially nicotine changes the chemistry of blood. This study was designed to investigate the adverse effect of smoking in hematological parameters in male and female smokers. A total of 200 subjects participated in the study including 100 males (50 smokers and 50 non-smokers) and 100 females (50 smokers and 50 non-smokers). Complete blood count (CBC) was performed to analyze the hematological changes between the smokers and non-smokers control group by using HumaCount $60^{\mathrm{TS}}$. Statistical analysis was performed in SPSS version 20. CBC test was performed to calculate the values of different parameters in blood. Significantly higher values of hemoglobin (Hb), Red Blood Cells (RBCs), White Blood Cells (WBCs) and MCHC (mean corpuscular hemoglobin concentration) were observed in male smokers $(\mathrm{P}<0.05)$ than non-smokers. Female smoker showed significant increase in $\mathrm{Hb}$ level and PCV (Hematocrit) as compared to nonsmokers and the difference was statistically significant $(P<0.05)$. Comparison of hematological changes in male smokers and female smokers showed significant increase in WBCs count of male smokers. Our findings showed that both male and female smokers have high leucocyte count that serves as a risk factor for certain diseases like cardiovascular diseases and chronic obstructive pulmonary disease.

Keywords: Complete blood count; Hematological parameters; Huma Count $60^{\mathrm{TS}}$; Smoking

Introduction

The process of burning tobacco in different

inhalation of produced smoke is known as form like biri, pipe, cigar and cigarette and smoking [1]. In all over the world cigarette smoking is a challenge for population health
Commented [j1]: Write in complete form before using abbreviation

Commented [j2]: Delete the red colored sentences. It need to be replace with 1-2 sentences of conclusion of study. 
and it is the major cause of death [2]. Cigarette contains four thousand chemicals and individuals who smoke cigarette are exposed with different destructive substances like nicotine, Carbon Monoxide free radicals and other gases [2]. It is the nicotine that makes tobacco addictive in nature [3]. Smoking is known to be the causative agent of different chronic disorders such as different respiratory infections, cancer and heart disorders [4].

The effect of smoking on blood hematology is severe and persistent [2]. Different hematological parameters like leukocyte count, erythrocyte count, platelet, as well as Hematocrit/PCV (packed cell volume), MCV (mean corpuscular hemoglobin), MCHC (mean corpuscular hemoglobin concentration) are found to be altered in smokers. Hematological parameters not only provide information about unstable condition of environment, but it also gives information regarding the condition of organism's health [5].

It is reported that erythrocyte count in adult male smokers is increased with minimum amount of smoking when compared with non-smokers [6]. Smoking increase concentration of hemoglobin in blood and it is due to $\mathrm{CO}$ exposure [7]. According to the study current smokers show significantly higher level of WBCs count as compared to non-smokers or passive smokers [8]. Nicotine is involved in release of hormone that increase WBCs count [9]. High level of RBCs and WBCs can cause inadequate flow of blood, enhanced viscosity and increased clotting [6]. The current study was conducted to evaluate the effect of smoking on the hematological profile of individuals and to determine if there is difference in the hematological parameters between smokers and non-smokers.

Materials and methods

The present study was conducted in Mohtarma Shaheed Benazir Bhutto General
Hospital, Quetta. A total of 200 subjects comprising 100 smokers (50 males and 50 females) and 100 non-smokers (50 males and 50 females) were recruited in the study to evaluate the hematological profile of both smokers and non-smokers.

Inclusion criteria

In both groups smokers and non-smokers were devoid of any infection/disease and were between ages of 20-60 years. Smokers included those who regularly smoked cigarette or hookah.

\section{Exclusion criteria}

Individuals having any disease, using any sort of drugs and those who donate or receive blood in last six months were excluded from the study. Pregnant females and also other forms smoking were excluded.

\section{Ethical consideration}

The study protocol was approved by the Ethical Review Committee of Sardar Bahadur Khan Women's University, Quetta and each subject gave an informed consent.

\section{Demographic and biochemical}

measurements

Data about medical history and other information such as age, marital status, daily activity, diet and educational status were collected from all subjects using a predesigned questionnaire. Information regarding number of cigarettes used per day, duration of smoking, stress level was collected from smokers. Blood pressure was measured by oscillometric method. Body mass index (BMI) were measured by dividing the body weight in kilograms by the height meter squared $\left(\mathrm{kg} / \mathrm{m}^{2}\right)$ as given by World Health Organization (WHO).

With the help of $5 \mathrm{ml}$ disposable syringe, $3 \mathrm{ml}$ venous blood sample was collected in EDTA anticoagulant blood container and mixed before analysis. These samples were subjected to HumaCount $60^{\mathrm{TS}}$ (Hematology analyzer) and sample was sucked by apparatus and the results were displayed on screen. Samples were analyzed within an 
hour after withdrawing blood to avoid variation in blood count.

\section{Statistical analysis}

Results were analyzed and interpreted by using statistical software SPSS (Statistical Package for Social Sciences) version 20. Values of hematological parameters were compared between smokers and non-smokers in male and female subjects by using "independent samples t-test". $P$ value less than 0.05 was considered as significant.

\section{Results}

The comparison of general characteristics such as age, educational status, BMI and blood pressure of 100 smokers (50 male and 50 female) and 100 non-smokers (50 male and 50 female) is given in (Table 1). The mean age of male smoker was $39.6 \pm 11.2$ $($ mean \pm SD) and non-smoker was 32.5 \pm 10.1 . The female smokers had mean age of $38.9 \pm 13.3$ and non-smoker female 32.7 \pm 7.4 . Among male smokers 36 percent had matriculate level of education and approximately half proportion $(52 \%)$ were above matriculate. More than half proportion of female smokers $(60 \%)$ were uneducated. High percentage of male smokers were overweight $(44 \%)$ whereas high percentage of female smokers $(36 \%)$ were healthy which indicated smoking had no adverse effect on BMI of female smokers than male smokers. Smoking increases the blood pressure. Rise in (Blood Pressure) systolic and diastolic blood pressure were observed in smokers of male and female (both) sexes as compared with non-smokers group.

Hematological parameters in male smokers and non-smokers

The comparative result of hematological parameters in male smoker and non-smokers is represented in (Table 2). There was statistically significant difference in $\mathrm{Hb}$, RBC, TLC and MCHC level between smokers and non-smokers with the $P$ values of $0.003,0.012,0.000$ and 0.031, respectively. Other parameters including platelet, neutrophil, lymphocyte, monocyte, PCV, MCV, MCH showed statistically no significant difference between male smokers and non-smoker $(P>0.05)$.

Table 1. General characteristics of smokers and non-smoker $(\mathbf{n}=200)$

\begin{tabular}{|c|c|c|c|c|c|}
\hline \multirow{2}{*}{$\begin{array}{c}\text { General } \\
\text { characteristics }\end{array}$} & \multirow{2}{*}{ Range } & \multicolumn{2}{c|}{ Smoker Group } & \multicolumn{2}{c|}{ Non-Smoker Group } \\
\cline { 3 - 6 } & $\begin{array}{c}\text { Male } \\
\text { Subjects }\end{array}$ & $\begin{array}{c}\text { Female } \\
\text { Subjects }\end{array}$ & $\begin{array}{c}\text { Male } \\
\text { Subjects }\end{array}$ & $\begin{array}{c}\text { Female } \\
\text { Subjects }\end{array}$ \\
\hline \multirow{4}{*}{ Age (years) } & Mean \pm SD & $39.6 \pm 11.2$ & $38.9 \pm 13.3$ & $32.5 \pm 10.1$ & $32.7 \pm 7.4$ \\
\cline { 2 - 6 } & $20-29$ & $8(16 \%)$ & $10(20 \%)$ & $22(44 \%)$ & $14(28 \%)$ \\
\cline { 2 - 6 } & $30-39$ & $18(36 \%)$ & $14(28 \%)$ & $16(32 \%)$ & $24(48 \%)$ \\
\cline { 2 - 6 } & $40-49$ & $14(28 \%)$ & $16(32 \%)$ & $8(16 \%)$ & $12(24 \%)$ \\
\cline { 2 - 6 } & $50-59$ & $10(20 \%)$ & $14(28 \%)$ & $4(8 \%)$ & $0(0 \%)$ \\
\hline \multirow{4}{*}{ BMI } & Mean \pm SD & $38.55 \pm 66.05$ & $27.94 \pm 5.36$ & $24.72 \pm 3.16$ & $28.09 \pm 5.56$ \\
\cline { 2 - 6 } & Healthy & $16(32 \%)$ & $18(36 \%)$ & $36(64 \%)$ & $4(8 \%)$ \\
\cline { 2 - 6 } & Underweight & $4(8 \%)$ & $0(0 \%)$ & $2(4 \%)$ & $2(4 \%)$ \\
\cline { 2 - 6 } & Overweight & $22(44 \%)$ & $14(28 \%)$ & $16(32 \%)$ & $14(28 \%)$ \\
\hline \multirow{3}{*}{ Education } & Obese & $8(16 \%)$ & $16(32 \%)$ & $0(0 \%)$ & $18(36 \%)$ \\
\cline { 2 - 6 } & Illiterate & $6(12 \%)$ & $30(60 \%)$ & $6(12 \%)$ & $24(48 \%)$ \\
\cline { 2 - 6 } & Matriculate & $18(36 \%)$ & $6(12 \%)$ & $26(52 \%)$ & $16(32 \%)$ \\
\cline { 2 - 6 } & Above matriculate & $26(52 \%)$ & $14(28 \%)$ & $18(36 \%)$ & $10(20 \%)$ \\
\hline $\begin{array}{l}\text { Blood pressure } \\
\text { (mmHg) }\end{array}$ & Systolic & $137.12 \pm 11.8$ & $132.0 \pm 9.5$ & $129.36 \pm 8.13$ & $126.60 \pm 9.0$ \\
\cline { 2 - 6 } & Diastolic & $87.48 \pm 8.08$ & $85.16 \pm 7.12$ & $83.48 \pm 6.15$ & $82.76 \pm 5.53$ \\
\hline
\end{tabular}


Arbab et al.

Table 2. Comparison of hematological parameters in male smokers and non-smokers

\begin{tabular}{|c|c|c|c|c|c|}
\hline \multirow{2}{*}{ Parameters } & \multicolumn{2}{|c|}{ Smokers } & \multicolumn{2}{|c|}{ Non-smokers } & \multirow{2}{*}{$P$ value } \\
\hline & Range & Mean \pm SD & Range & Mean \pm SD & \\
\hline Hb (g/dl) & $12-20$ & $15.6 \pm 1.83$ & $8-15$ & $14.1 \pm 1.35$ & $0.003 *$ \\
\hline $\operatorname{RBC}\left(10^{12} / 1\right)$ & $4.13-7.48$ & $5.7 \pm 0.76$ & $3.89-6.17$ & $5.2 \pm 0.54$ & $0.012 *$ \\
\hline TLC (10 $9 / 1)$ & $3.50-14.49$ & $7.63 \pm 2.43$ & $1.13-7.77$ & $5.25 \pm 1.3$ & $0.000 *$ \\
\hline Platelet $\left(10^{9} / \mathrm{l}\right)$ & $119-840$ & $256.72 \pm 143.4$ & $104-301$ & $214.40 \pm 54.5$ & $0.174^{\mathrm{NS}}$ \\
\hline Neutrophil (\%) & $46.80-80.40$ & $58.5 \pm 8.10$ & $34-74$ & $58.8 \pm 9.9$ & $0.889^{\mathrm{NS}}$ \\
\hline Lymphocyte (\%) & $12.90-46.50$ & $31.69 \pm 7.59$ & $18-46$ & $31.14 \pm 8.5$ & $0.601^{\mathrm{NS}}$ \\
\hline Monocyte (\%) & $3.8-13.6$ & $8.11 \pm 2.34$ & $3.5-10$ & $7.3 \pm 1.79$ & $0.189^{\mathrm{NS}}$ \\
\hline PCV (\%) & $37.20-65.18$ & $48.61 \pm 5.69$ & $31.8-71.90$ & $45.97 \pm 7.4$ & $0.168^{\mathrm{NS}}$ \\
\hline $\operatorname{MCV}(\mathbf{f l})$ & $42.50-116$ & $84.67 \pm 14.24$ & $60-98$ & $83.91 \pm 9.1$ & $0.823^{\mathrm{NS}}$ \\
\hline MCH (pg) & $18.50-33.70$ & $27.92 \pm 4.37$ & $18.9-30.9$ & $26.1 \pm 2.84$ & $0.094^{\mathrm{NS}}$ \\
\hline MCHC (g/dl) & $30-33.70$ & $33.05 \pm 1.02$ & $28.10-34.6$ & $31.20 \pm 1.60$ & $0.031 *$ \\
\hline
\end{tabular}

$\mathrm{P}^{*}$ (Significant), $\mathrm{P}^{\mathrm{NS}}$ (Not significant)

$\mathrm{Hb}$ (Hemoglobin), RBC (red blood cells), TLC (total leukocyte count), PCV (packed cell volume), MCV (mean corpuscular volume), $\mathrm{MCH}$ (mean Corpuscular hemoglobin), MCHC (mean corpuscular hemoglobin concentration).

Hematological parameters in female smokers and non-smokers

Smokers exhibited higher levels of $\mathrm{Hb}$ and PCV as compared to non-smokers among females and the difference was statistically significant $(P<0.05)$. Rise in TLC was also observed in female smokers but this difference was statistically non-significant $(P>0.05)$. Other parameters showed no significant change between two groups (Table 3).

Table 3. Comparison of hematological parameter in female smokers and non-smokers

\begin{tabular}{|c|c|c|c|c|c|}
\hline \multirow{2}{*}{ Parameters } & \multicolumn{2}{|c|}{ Smokers } & \multicolumn{2}{|c|}{ Non-smokers } & \multirow{2}{*}{$\begin{array}{c}P \\
\text { Value }\end{array}$} \\
\hline & Range & Mean \pm SD & Range & Mean \pm SD & \\
\hline Hb (g/dl) & $10.60-19.80$ & $14.55 \pm 2.5$ & $8.90-15$ & $12.7 \pm 1.6$ & $0.006 *$ \\
\hline $\operatorname{RBC}\left(10^{12} / \mathrm{l}\right)$ & $3.44-68.50$ & $7.82 \pm 12.6$ & $2.88-6.12$ & $4.9 \pm 0.7$ & $0.27^{\mathrm{NS}}$ \\
\hline $\operatorname{TLC}\left(10^{9} / 1\right)$ & $2-11.44$ & $5.79 \pm 2.18$ & $1.09-7.26$ & $4.9 \pm 1.6$ & $0.14^{\mathrm{NS}}$ \\
\hline Platelet $\left(10^{9} / \mathrm{l}\right)$ & $100-810$ & $205.2 \pm 144.4$ & $147-376$ & $232.68 \pm 51.0$ & $0.31^{\mathrm{NS}}$ \\
\hline Neutrophil (\%) & $38-85$ & $61.3 \pm 11.3$ & $18.8-80.70$ & $60.6 \pm 12.7$ & $0.82^{\mathrm{NS}}$ \\
\hline Lymphocyte (\%) & $12.9-55.50$ & $32.18 \pm 10.7$ & $12-43.60$ & $29.6 \pm 8.77$ & $0.36^{\mathrm{NS}}$ \\
\hline Monocyte (\%) & $1.20-10.90$ & $5.96 \pm 1.82$ & $1.70-9.60$ & $5.89 \pm 1.77$ & $0.89^{\mathrm{NS}}$ \\
\hline PCV (\%) & $27.70-64.6$ & $48.4 \pm 9.7$ & $28.64-50.4$ & $41.93 \pm 5.5$ & $0.006^{*}$ \\
\hline MCV (fl) & $63-122$ & $86.8 \pm 11.85$ & $57-104$ & $82.14 \pm 11.6$ & $0.16^{\mathrm{NS}}$ \\
\hline MCH (pg) & $19-39$ & $27.26 \pm 4.3$ & $17.6-33.50$ & $25.68 \pm 3.9$ & $0.18^{\mathrm{NS}}$ \\
\hline MCHC (g/dl) & $29-35$ & $31.52 \pm 1.35$ & $29.30-33.9$ & $31.24 \pm 1.21$ & $0.43^{\mathrm{NS}}$ \\
\hline
\end{tabular}

$\mathrm{P}^{\mathrm{NS}}$ (Not significant), P* (Significant)

Hematological parameters in male and female smokers

Comparison of male and female smokers showed significant change $(P<0.05)$ in TLC with mean of $7.6310^{9} / 1$ in male and $5.7910^{9} / 1$ in female. Male smokers also showed higher level of monocyte as compared to female smokers $(8.11 \%$ vs $5.96 \%)$. No significant difference $(P>0.05)$ was observed in other 
Pure Appl. Biol., 8(1): 866-872, March, 2019

http://dx.doi.org/10.19045/bspab.2019.80028

hematological parameters between male and female smokers (Table 4).

Table 4. Comparison of hematological parameters between male smokers and female smokers

\begin{tabular}{|c|c|c|c|c|c|}
\hline \multirow{2}{*}{ Parameter } & \multicolumn{2}{|c|}{ Male smokers } & \multicolumn{2}{c|}{ Female smokers } & \multirow{2}{*}{ P value } \\
\cline { 2 - 5 } & Range & Mean \pm SD & Range & Mean \pm SD & \\
\hline Hb (g/dl) & $12-20$ & $15.6 \pm 1.8$ & $10.60-19.80$ & $14.55 \pm 2.5$ & $0.10^{\text {NS }}$ \\
\hline RBC (10 $\left.^{\mathbf{1 2}} / \mathbf{l}\right)$ & $4.13-7.48$ & $5.7 \pm 0.76$ & $3.44-68.50$ & $7.82 \pm 12.6$ & $0.4^{\text {NS }}$ \\
\hline TLC (10 $/ \mathbf{l})^{*}$ & $3.50-14.49$ & $7.63 \pm 2.34$ & $2-11.44$ & $5.79 \pm 2.18$ & $0.006^{*}$ \\
\hline Plt 10 $/ \mathbf{l})$ & $119.0-840$ & $256.72 \pm 143.4$ & $100-810$ & $214.40 \pm 54.5$ & $0.212^{\text {NS }}$ \\
\hline Neutrophil (\%) & $46.8-80.40$ & $58.5 \pm 8.10$ & $38-85$ & $61.3 \pm 11.3$ & $0.316^{\text {NS }}$ \\
\hline Lymphocyte (\%) & $12.9-46.50$ & $31.69 \pm 7.59$ & $12.90-55.50$ & $32.18 \pm 10.7$ & $0.85^{\text {NS }}$ \\
\hline Monocyte (\%) & $3.8-13.6$ & $8.11 \pm 2.34$ & $1.20-10.90$ & $5.96 \pm 1.82$ & $0.001^{*}$ \\
\hline PCV (\%) & $37.2-65.18$ & $48.61 \pm 5.69$ & $27.70-64.6$ & $48.4 \pm 9.7$ & $0.92^{\text {NS }}$ \\
\hline MCV (fl) & $42.50-116$ & $34.67 \pm 14.24$ & $63-122$ & $86.8 \pm 11.85$ & $0.55^{\text {NS }}$ \\
\hline MCH (pg) & $18.5-33.70$ & $27.92 \pm 4.37$ & $19-39$ & $27.26 \pm 4.3$ & $0.59^{\text {NS }}$ \\
\hline MCHC (g/dl) & $30-33.70$ & $33.05 \pm 1.02$ & $29-35$ & $31.52 \pm 1.35$ & $0.12^{\text {NS }}$ \\
\hline
\end{tabular}

$\mathrm{P}^{\mathrm{NS}}$ (Not significant), $\mathrm{P} *$ (Significant)

\section{Discussion}

Current study showed remarkable increase in hemoglobin concentration in both male and female smokers as compared to non-smokers. Significant increase in RBCs count, TLC and MCHC in male smokers were observed. Female smokers showed higher levels of RBCs, WBCs, neutrophil, lymphocyte, $\mathrm{MCV}, \mathrm{MCH}$ and $\mathrm{MCHC}$ but these values were not significantly different than nonsmokers female. Comparison of hematological parameters in male smokers and female smokers showed increased leucocyte count and monocyte in male smokers while other parameters showed no significant change between two groups.

A study conducted by Shenwai and his colleagues [10] reported significant increase in total leucocyte count and no significant increase in differential leucocyte count in smokers which is similar to the findings of the current study but result of RBCs count is opposite. Our study showed increase in hemoglobin concentration and RBCs compared to above study. It was concluded by Jain et al. that there was significant increase in leucocyte count and hemoglobin concentration in male smokers [11]. PCV value was observed higher in smokers but our study showed higher PCV values in female smokers but not significant increase in male smokers. In some study smokers were reported with higher values of WBCs, RBCs, $\mathrm{Hb}$, PCV, and MCHC. While other parameters showed no significant change between smokers and non-smoker males [2]. Leukocytosis is caused by persistent cigarette smoking and it leads to increased level of PMNLs (polymorphonuclear leukocyte) and band cell in blood circulation which stimulate bone marrow for release of mature as well as immature polymorphonuclear leukocyte and raise the level of WBCs count [12].

Our study showed increased hemoglobin concentration, RBCs and WBCs count in smokers and results is corelated with the previous study by Abdulnabi et al. [3]. A study conducted in Tamil India showed that hemoglobin was significantly higher in male smokers $(\mathrm{P}=0.05)$ and WBCs count showed highly significant increase in smokers $(\mathrm{P}=0.000)$. RBCs count was not significantly different between smoker and non-smokers. PCV was found to be higher in male smokers 
Arbab et al.

while our study showed no significant rise in PCV in male smokers but in female [13]. It was investigated the effect of smoking on hematological parameters and concluded that cigarette smokers possess high value of hemoglobin concentration in their blood. Other hematological parameters including WBCs, RBCs, PCV, MCV, MCH, MCHC were not significantly higher in smokers when compared with nonsmoker [13]. Findings showed rise in the hemoglobin and RBCs count in both male and female smokers as observed in our study. They also observed significantly high level of hematocrit, but our study showed increased hematocrit in female smokers.

A similar result as ours was reported regarding hemoglobin concentration in smokers but does not for PCV which was significantly higher in male smokers in study [16]. A significant rise in $\mathrm{Hb}, \mathrm{WBC}, \mathrm{MCV}$ and $\mathrm{MCH}$ in male smokers than nonsmokers. Mean value of MCHC was nearly equal in smokers and non-smokers whereas our study showed equal mean values of $\mathrm{MCHC}$ in female smokers but significantly higher MCHC level in male smokers [16].

\section{Conclusion}

Tobacco cigarette smoking is one of the major leading causes of death throughout the world. Smoking has both acute and chronic effect on hematological parameters. In conclusion, the present study indicated that continuous cigarette smoking caused increase in hematological parameters such as hemoglobin, hematocrit, red blood cells count, white blood cells count, and mean corpuscular hemoglobin concentration and these alterations might be associated with a greater risk for developing cardiovascular diseases, polycythemia Vera, atherosclerosis and/or chronic obstructive pulmonary disease.

\section{Authors' contributions}

Conceived and designed the experiments: FA Bukhari \& M Arbab, Performed the experiments: Z Batool, Analyzed the data: Afsheen, H Ali \& M Naeem, Contributed reagents/ materials/ analysis tools: $\mathrm{N}$ Tariq, Wrote the paper: MM Tariq, M Arbab \& T Hameed.

\section{References}

1. Khan MI, Bukhari, MH, Akhtar MS \& Brar S (2014). Effeect Of Smoking on Red Blood Cells count, hemoglobin concentrtion and red cell indices. Pak $J$ Med Health Sci 8: 361-364.

2. Asif M, Karim S, Umar Z, Malik A, Ismail T, Chaudhary A \& Rasool M (2013). Effect of cigarette smoking based on hematological parameters: comparison between male smokers and non-smokers. Turk J Biochem 38(1): 7580.

3. Abdulnabi BM (2015). Smoking Effects on Hematological Parameters in Human. Val Inter J 2: 1255-1259.

4. Alsalhen KS \& Abdalsalam RD (2014). Effect of cigarette smoking on liver functions: a comparative study conducted among smokers and nonsmokers male in El-beida City, Libya. Inter Curr Pharm J3(7): 291295.

5. Francesco F, Satheeshkumar P, Senthil Kumar D, Caterina F \& Giuseppe P (2012). Comparative study of hematological and blood chemistry of Indian and Italian Grey Mullet (Mugil cephalus Linneaus 1758). HOAJ Biol 15 .

6. Sherke BA, Vadapalli K, Bhargava DV, Sherke AR \& Gopireddy MMR (2016). Effect of number of cigarettes smoked per day on red blood cell, lecocyte and platelet count in adult Indian male smokers-A case control study. Inter $J$ Med Res Health Sci 5(2): 13-17.

7. Shah BK, Nepal AK, Agrawal M \& Sinha AK (2012). The effects of cigarette smoking on hemoglobin levels compared between smokers and non- 
smokers. Sunsari Technical College J 1(1): 42-44.

8. Tell GS, Grimm RH, Vellar OD \& Theodorsen L (1985). The relationship of white cell count, platelet count, and hematocrit to cigarette smoking in adolescents: the Oslo Youth Study. Circulation 72(5): 971-974.

9. Jain R \& Mukherjee K (2003). Biological basis of nicotine addiction. Indian $\quad J$ Pharmacol 35(5): 281-289.

10. Shenwai MR \& Aundhakar NV (2012). Effect of cigarette smoking on various haematological parameters in young male smokers. Indian J Basic Appl Med Res 2(5): 386-92.

11. Rajan AI, Joshi AR \& Hajyzadegan E (2014). Effect of cigarette smoking on leukocytes count in human adult males. Inter J Physiol 2(1): 107.

12. Lakshmi A, Anandhi Lakshmanan GKP \& Saravanan A (2014). Effect of intensity of cigarette smoking on haematological and lipid parameters. $J$ Clin Diagno Res 8(7): BC11.

13. Nadia MM, Shamseldein HA \& Sara AS (2015). Effects of Cigarette and Shisha Smoking on Hematological Parameters: An analytic case-control study. Inter Multispeciality J Health 10: 44-51.

14. Kumar J, Kumar G, Sharma A, FARHAN AK \& Sharma S (2012). The Effect of Smoking on the Blood Parameters of Young Adults. J Clin Diagn Res 6(7): 1244-1247.

15. Tirlapur VG, Gicheru K, Charalambous BM, Evans PJ \& Mir MA (1983). Packed cell volume, haemoglobin, and oxygen saturation changes in healthy smokers and non-smokers. Thorax 38(10): 785787.

16. Kung CM, Wang HL \& Tseng ZL (2008). Cigarette smoking exacerbates health problems in young men. Clin Invest Med 31(3): 138-149. 